\title{
Study on Scene Play Teaching of Higher Vocational English Based on Improving English Communicative Competence
}

\author{
Juanyin Liu \\ Hebei College of Industry and Technology, Shijiazhuang, 050091, China
}

Keywords: English communicative competence; higher vocational English; scene play teaching

\begin{abstract}
English teaching reform continuously deepens, English teaching mode is also adjusted correspondingly to adapt cultivation of students' comprehensive English quality. Higher vocational colleges are colleges to cultivate applied talents for society. After students leave colleges, they will be engaged in technical and practical work in society. Traditional exam-oriented education and single English knowledge transmission of knowledge cannot cultivate social high quality requirement for talents. Based on quality-oriented education, higher vocational English implements English course reform and breaks through obsolete English teaching mode. Especially in English communicative competence, theory teaching and practice teaching are combined to promote mutual exchange between students and teachers and among students. Besides, scene play teaching methods is introduced to create practice space in classroom and make students experience joys of English communication in classroom so as to mobilize students' initiative, consciousness and creativity of English study.
\end{abstract}

\section{Introduction}

The purpose of language teaching is to promote exchange. English as a universal foreign language in the world is widely applied. In higher vocational English teaching, English communicative competence teaching is comprehensive, including multiple subjects such as English, sociology and psychology. In general, the quality of higher vocational college students is not high. Especially in English study aspect, their foundation is weak. Compared with English listening teaching and reading teaching, it is hard to improve English communicative competence of higher vocational college students. Situational teaching is introduced in English teaching to stimulate students' English study interest. While activating classroom atmosphere, it is also necessary to guide students for self-training of English communicative competence to cultivate lifelong English study habit.

\section{Necessity of applying scene play teaching in higher vocational English class}

(I) Transform English study resource to scene play teaching factor to mobilize students’ English study enthusiasm

With regard to students' English study, English Curriculum Standards propose student-dominated comprehensive language learning objectives to guide students to improve English study atmosphere. In specific teaching activity, to carry out English teaching with multiple forms, teachers should transform English study resources to scene play factors to conduct scene play teaching so as to improve English learning effects. Besides, from the perspective of English teaching, English scene play teaching caters to current higher vocational English teaching form and carries out English scene play teaching which becomes formalistic in actual life. In English classroom teaching, scene play is conducted in the form of simulating life miniature. This not just creates English teaching environment which conforms to students' psychological need, but also mobilizes students' enthusiasm for English study.

(II) English scene play teaching can rapidly improve students’ comprehensive English quality

English study not just aims to learn to apply English language tools, but also promotes English cultural exchange. So, English teaching needs to create language situations matched with English teaching contents to guide students to boost English expression ability and cultivate their English 
listening and speaking ability as well as English thinking ability. The most visual English scene play teaching should adapt to students' activities. So, during the implementation of English scene play teaching, the scene play should be closely related to students' life so that students can apply English in "familiar" environment. This can promote students to give play to their potential ability and then rapidly improve their comprehensive English quality.

(III) English scene play teaching can rapidly boost English communication level

English classroom teaching is dominated by English communication, involving English listening comprehension, spoken language and English culture etc. The implementation of English scene play teaching meets students' English listening and speaking training. Especially, English spoken language teaching can improve students' English reaction capacity to accelerate their English thinking speed. Seeing from realistic teaching form of English scene play, it mainly aims to improve students' English play simulation ability. It not just creates favorable English language environment, but also can train students' accurate pronunciation. Students exchange with each other in standard English. In this way, students' English listening and speaking ability can make rapid progress and absorb knowledge in multiple aspects. It is thus very necessary to promote the improvement of students' comprehensive English quality.

\section{Necessary factors for improving students’ English communicative competence}

(I) Courage students to speak English

For higher vocational college students, since they have poor English foundation, they have a sense of fear for English study and are unwilling to speak English. British linguist Macintyre and Gardner proposes his own views on such phenomenon, i.e. the reason why students have negative mood for English study lies in limited English communication. They generate psychological shadow due to impacts of English performance. In particular, they are unwilling to speak. To improve students' English communicative competence, English teachers should guide students to be brave in speaking English.

(II) Cultivate students to establish English thinking

In the opinion of American educationalist Benjamin Bloom, the establishment of English thinking mode will go through memory and comprehension stags and then the stage of application, analysis, evaluation and creation. Memory and comprehension mainly utilizes students' visual thinking to guide students to comprehend English articles with thinking icons. The stage of application, analysis, evaluation and creation unfolds in the form of heuristic teaching. Students should screen the necessary information from complex information. The process of screening and sorting information is the thinking process. Then, they return English to real life and unfold with scene play teaching mode. Their English communicative competence can improve through such training.

(III) Students should be able to master correct pronunciation rules

In language interaction activities, only when one understands what others say can he communicate with them with correct language. This means when students apply language, they should be able to master correct pronunciation rules and improve language cognition ability so as to avoid unnecessary mistakes. During English communication, it is required to comply with pronunciation habits of English native speakers, i.e. pronunciation of English should be based on international phonetic signs, and correct pronunciation rules should be mastered. For example, when two consonants are continuous, the first one can not be read out. In goo(d) luck, the pronunciation of "d" is usually not read out. When a word ends with a consonant, and the last word starts with a vowel, the consonant and the vowel should be combined during pronunciation. For example, in Than (k) (you) very much, there is "consonant + vowel" liaison. The pronunciation of inter-tooth space should be accurate. When pronouncing "th" in through and thanks, the tip of the tongue should contact the upper teeth. Only when the pronunciation is correct, one can have sensitiveness to voice when listening and correctly comprehend English language. 


\section{Application of scene play in improving English communicative competence}

(I) Scene play teaching can guide students to establish cross-cultural awareness

Higher vocational college students reach to few English original works. Since they have poor English foundation, they will not be interested in original English movies. Therefore, they will not deeply know language and culture difference. in order to boost English communicative competence, students should know differences between culture of English-speaking countries and Chinese culture. When English teachers carry out English scene play teaching, they should highlight culture features of English-speaking countries and the contents closely related to students' life for their comparative study. For example, scene play with the theme of family visit involves appellations of friends and relatives. Due to different contexts, language expression will comply with local language and culture. In China, we call our parents "father" and "mother" and call their friends "uncle" and "aunt”. In English-speaking countries, they often call their parents their names. From the perspective of English culture, children and parents are equal. Regardless of the age, they can directly call names to show amity. For brothers and sisters of their parents, they call "Aunt" or "Uncle" and add their names, such as "Aunt Mary" and "Uncle Lauren". When seeing friends" parents, native speakers call them with "Mrs." or "Mr." and add the family name. It is worth stressing that, in Chinese language context, people often say "Good morning, Teacher Xu." according to Chinese habits. Actually, such expression does not comply with language expression of English-speaking countries. To avoid language faults, English teachers should base language on cultural background in scene play teaching to avoid language comprehension deviation and cultivate students' tolerance of different cultures.

(II) Scene play teaching can utilize visual material objects and props to mobilize students' enthusiasm

In scene play teaching, teachers should fully utilize various material objects including pictures and various teaching tools to mobilize students' visual thinking to understand words' meanings and cultivate them to understand problems with English thinking. For example, when English scene teaching is set for higher vocational college students majoring in tourism, teachers can design travelling scenes, prepare some props and articles tour guides need in some travelling situations so that students can experience relevant problems in English communication while performing. For overseas tourism, passport is needed. Teachers can ask several students to prepare 10min scene play related to passport before class and require them preparing some relevant material objects. Through practical operation, students can further deepen cognition of passport use and improve communicative competence.

(III) Create favorable communication atmosphere in scene play teaching

For English learners, favorable communication atmosphere can make learning atmosphere more relaxing. Especially in English context, if colleges can set up corresponding English training platform rather than limited to classroom scene play teaching, English language environment will form in campus. This is very beneficial to promoting English communicative ability. For instance, higher vocational colleges can regularly hold minitype scene play contest and require students designing English scene play according to their major and future occupational scenes. In this way, students can combine their major with English communication to independently study English knowledge. During the activities, foreign teachers can be invited to judge and guide to provide students with the opportunities of directly communicating with native English speakers. It is required to create pure English environment as far as possible to improve students' English communicative competence.

(IV) Apply multimedia to assist scene play teaching

Currently, higher vocational colleges generally apply multimedia to assist teaching. Especially in English teaching, vivid images and proper background music can make English classroom teaching more vivid. English is a language culture. Since scene play is performed in limited classroom space, the shortage of English culture often appears. With multimedia-assisted teaching, context range can expand and students can understand more English communication features. For example, English interview scene can be created for students. The background of the scene can be made with 
multimedia courseware. Such interview scene includes an interviewer, a recorder and applicants. The whole process of the scene play is in English context. For exchanges among students, teachers can apply multimedia courseware to prompt them. Meanwhile, background voice can be matched in allusion to students; English expression state so that the interview scene can be active. Students are in a simulated English interview scene, which can not just accumulate interview experience, but also improve English communicative competence in interview scene.

\section{Conclusions}

In conclusion, the main purpose of English learning is to communicate. Higher vocational colleges apply English scene play teaching, which aims to guide students to be place themselves in English language culture, make them establish English thinking, improve language communicative ability, proficiently apply English language and flexibly cope with various students. English teachers as instructors of English learning should combine students' features to create interactive teaching platform to improve English teaching efficiency.

\section{References}

[1] Liu Xiaotang, On application of situational teaching method in higher vocational English for tourism [J]. Business Economy, 2011 (05)

[2] Chen Lichun, Factors influencing English communicative competence of college students and countermeasures [J], Journal of Jixi University, 2010 (01)

[3] Yin Xiaoxia, Attempt for English scene play teaching in vocational high schools under new curriculum reform [J]. Science and Technology Communication, 2011 (03)

[4]H. D. Brown. Principles of Language Learning and Teaching [M]. Foreign Language Teaching and Research Press, 2000.

[5] Zhang Jiaoyan, Han Lu, Application of scene play performance in oral English teaching [J]. Science \& Technology Information (academic research), 2008 (03)

[6] Li Jilin, Exploration and thought of “situation education” [J]. Educational Research, 2006

[7]Marion Williams \& Robert L. Burden Psychology for Language Teachers [M]. Foreign Language Teaching and Research Press, 2000. 